\title{
SAÚDE E TRABALHO DOCENTE: A ESCOLA COMO PRODUTORA DE NOVAS FORMAS DE VIDA
}

TEACHING AND HEALTH:THE SCHOOL AS PRODUCER OF NEW FORMS OF LIFE

\author{
Maria Elizabeth Barros 1 \\ Dorotéia Carlini Zorzal 2 \\ Fernanda Silva de Almeida 3 \\ Roberta Zacché Iglesias 4 \\ Vivian Gomes Vieira de Abreu 5
}

\begin{abstract}
Resumo $\mathrm{O}$ artigo tem como tema as articulações saúde-trabalho docente. Apresenta uma experiência vivida numa escola municipal da rede de ensino da cidade de Vitória, no Espírito Santo. Pauta-se nas abordagens de G. Canguilhem, na ergonomia de linhagem francesa e na ergologia para realizar o processo de pesquisa-intervenção. Parte do princípio de que o vivido na escola afirma a perspectiva segundo a qual saúde é possibilidade de produzir novas normas, ou seja, novas formas de vida. Nessa direção de análise, buscou criar espaços de diálogo e tensionamento na escola para que outros modos de trabalhar, favorecedores de saúde, pudessem se instituir.
\end{abstract}

Palavras-chave cotidiano escolar; psicologia; saúde.

Abstract This article focuses on the relationship between teaching and health. It presents an experience in a public school in Vitória, Espírito Santo. The intervention research was based on the ideas of G. Canguilhem, on French ergonomics, and on ergology. Its basic premise is that experience at school confirms the concept that health is the possibility of producing new norms, that is, new forms of life. In this sense, the research sought to produce dialogue and tension at school so that other health-promoting modes of work could be implemented.

Keywords daily school life; psychology; health. 


\section{Introdução}

A história que nos propomos a contar aqui, neste texto, é o resultado de 16 meses de trabalho no turno matutino de uma escola da rede municipal de Vitória, no Espírito Santo. História que não parte de um começo determinado nem de um fim predeterminado, mas do meio, do processo de sua constituição. História, portanto, que não parte de fundamentos, pois não compartilhamos da idéia dos 'começos originários' nem do 'fim da história'; ao contrário, afirmamos que os seres humanos fazem história incessantemente na sua vida cotidiana. Um cotidiano que é multifacetado, em devir. O tempo e as relações sociais não podem ser reduzidos à sua linearidade quantitativa, o que não significa negar o tempo cronológico que também constitui esse cotidiano. Falamos de uma vida que se transfigura na gestação dessa cotidianidade, como modos de viver sem estilo definido, mergulhada numa historicidade em que os humanos se encontram e desencontram de si mesmos.

Acreditamos que o que foi produzido entre o grupo de psicologia e os educadores - e aqui, nesta categoria, consideramos todos aqueles que participam de algum modo do processo de formação dos alunos, ou seja, professores, equipe técnica, pessoal da limpeza, da cantina, da secretaria, pais - não acabará com a nossa saída da escola, pois criamos todos os dias novas formas de fazer e ser. Os grupos humanos fazem escolhas, exploram os recursos existentes nos meios que habitam, trabalham, reorganizam “(...) desta ou daquela maneira para produzir novas combinações: essas combinações novas 'fazem história', abrem novos horizontes, colocam novas tarefas ao conhecimento (...)" (Schwartz, 2003, p. 6-7).

A história que narraremos é baseada em uma memória afetiva, cognitiva, mas, principalmente, sensorial. Para transmitir o tom dos objetos, o clima, a paisagem e a vida da escola, é preciso mais do que categorias conceituais e definições que possam 'desvendá-las'. Quando falamos desse trabalho, nossas lembranças vêm impregnadas também com o cheiro da comida servida na cantina, com a cor dos murais, com o barulho e os esbarrões dos meninos e meninas correndo no pátio, na sala de aula, na quadra... com o burburinho na hora do 'cafezinho' na sala dos professores, com o sabor nem sempre doce, mas intenso, das experiências.

Durante o período em que estivemos na escola, percorremos corredores, distribuímos merenda para as crianças, entramos nas salas de aula, participamos das reuniões de planejamento, de algumas festividades, criando vínculos. Enfim, buscamos viver aquele cotidiano não como observadores neutros, imparciais, mas como participantes de um processo de construção de uma nova forma de ser trabalhador e pesquisador, e poder captar os movimentos que são produzidos a cada momento com todas as suas diferentes in- 
tensidades, deparar-se com as surpresas e os acontecimentos, perceber e ampliar as resistências que se colocam contra os processos de imobilização, dar visibilidade ao que os professores nomeiam de 'dar conta do serviço'. Ser pesquisador é, aqui, nessa perspectiva, captar o que acontece no ambiente de trabalho para produzir, coletivamente, transformação.

Também não tínhamos a pretensão de formular generalizações, e sim falar do trabalho efetivamente realizado, de trabalho concreto que tem marcas singulares em cada coletivo. Focamos nossa atenção no funcionamento peculiar daquela escola, tentando entender como seus integrantes sentiam, viviam e respondiam às reformas educacionais que impõem modelos a serem seguidos, ao sucateamento do ensino público, à precarização e desvalorização da atividade docente, à dupla e até tripla jornada de trabalho. Sabemos que essas questões constituem, hoje, a educação brasileira, mas o que perseguíamos era a maneira particular como se materializavam as práticas educacionais no chão daquela escola localizada num dos morros do município de Vitória, como os educadores resistiam aos processos de desvitalização impostos pelas prescrições do trabalho feitas pela Secretaria Municipal de Educação (Seme), enfim, a forma como as pessoas ali trabalhavam, conviviam, como suas histórias se cruzavam e que relações estabeleciam.

Partimos de uma convicção: o trabalho no capitalismo não é apenas sofrimento. Quando dizemos trabalho, falamos também criação. O trabalho não é jamais pura execução de tarefas, já que é impossível que não haja atividade, é impossível ficar no prescrito, naquilo que é determinado antes da realização do trabalho6. Ao contrário, cada trabalhador se apropria de uma maneira singular do que lhe é proposto. Trabalhar é gerir a variabilidade, o imprevisto, fazendo escolhas, correndo riscos, inventando. O trabalho não envolve só repetição e é, antes de tudo, um processo coletivo que enuncia patrimônios, conquistas, lutas culturais, técnicas, sociais e políticas. Essa possibilidade de criar novas normas de trabalho-vida, esse estado contínuo de instabilidade que possibilita a ação-criação é o que nomeamos saúde. A doença passa a ter, então, uma conotação que sinaliza para a dificuldade de alterar uma situação que agride física e psiquicamente, produzindo insatisfação e sofrimento (Canguilhem, 2001). Buscamos, portanto, analisar a relação trabalho-saúde na escola em questão, compreender os processos que contribuem para o adoecimento e a insatisfação no ambiente de trabalho e identificar como esses educadores constroem estratégias para se defenderem e para darem sentido ao que fazem.

Assim, com o objetivo de pensar a saúde do trabalhador da educação, escolhemos como caixa de ferramentas conceitual-metodológica a abordagem ergológica, que vem sendo construída na França (Schwartz, 2002) e tem como ponto de partida as transformações que vêm ocorrendo nos mun- 
dos do trabalho. A ergologia tem como princípio o diálogo imprescindível entre os conhecimentos produzidos pela diferentes disciplinas e os saberes construídos na experiência dos trabalhadores no seu cotidiano. Concordando com Alvarez e Telles (2004), diríamos que existem convergências importantes entre

“(...) essa forma de produção de conhecimentos sobre o trabalho e suas relações e a proposta da saúde do trabalhador, marcadas especialmente pela herança das idéias difundidas pelo Modelo Operário Italiano das décadas de 1960-1970, por meio da obra do médico e psicólogo do trabalho Ivar Odonne" (Alvarez e Telles, 2004, p. 91).

Foi então, a partir do diálogo com a abordagem ergológica, que buscamos pensar as questões da produção de saúde dos educadores de uma escola pública do município de Vitória, à luz da ergologia. Partimos do princípio que saúde do trabalhador é, principalmente, uma direção de investigação e intervenção nas questões relativas à saúde do educador (no nosso caso), uma maneira de ver e intervir nas situações de trabalho a partir das diferentes disciplinas e profissões e dos olhares dos trabalhadores que podem contribuir para o entendimento das articulações entre o trabalho que desenvolvem na escola e sua saúde. Foi nessa direção que buscamos contribuições dos instrumentos epistemológicos-conceituais-metodológicos da ergologia, que nos oferece um

(...) modelo de produção de conhecimento que converge com os princípios desse campo (nomeado Saúde do Trabalhador), uma vez que propõe a articulação entre os materiais gerados pelas diferentes disciplinas científicas (pólo dos conceitos), os saberes e valores gerados pelas experiências dos trabalhadores nas atividades (pólo das forças de convocação e de reconvocação) e, por fim, o pólo das exigências éticas e epistemológicas, que propicia o encontro fecundo dos dois primeiros. Esse terceiro pólo é a liga do dispositivo, pois trata da ética necessária à construção das relações de parceria, apoiada em determinada filosofia da humanidade, numa maneira de ver o outro como seu semelhante (Alvarez e Telles, 2004, p. 102, grifo nosso).

Consideramos, portanto, que a abordagem ergológica, ao não privilegiar as generalizações, almejada por algumas ciências, busca não neutralizar os aspectos singulares da experiência em análise, consideradas como fonte potencial para a compreensão das situações de trabalho. A ergologia pode enriquecer a concepção de trabalho que adotamos no campo da saúde do trabalhador na medida em que coloca o processo de trabalho como categoria central de análise da relação saúde-trabalho. Destacamos, ainda, que a abor- 
dagem ergológica afirma que é no intercâmbio com os trabalhadores que poderemos avançar nas investigações no âmbito da saúde do trabalhador, pois é impossível conhecer a atividade de trabalho a priori, uma vez que é sempre enigmática.

\section{Sobre a pesquisa-intervenção}

Ao adentrarmos o cotidiano de uma escola da rede municipal de ensino, escolhida para a realização da pesquisa, muitas vezes nos deparamos com educadores tomados por um niilismo ${ }^{7}$ que nega a vida, depreciando-a, atribuindo-lhe um valor de nada, como se não soubessem o que é criação, anseio. Uma vida reativa que não possui sequer vontade de desaparecer, pois sonha com uma extinção passiva. Tudo parecia vão, igual, terminado... “Todas as fontes secaram para nós e o mar retirou-se. Todo o solo se esvai, mas o abismo não quer engolir-nos. Ai! Onde existirá ainda um mar em que nós nos possamos afogar? De fato, estamos já muito fatigados para morrer" (Deleuze, 1976, p. 56). Na trilha de Nietzsche, diríamos que, muitas vezes, os educadores se aproximavam de um rebanho resignado e estagnado ou que anseia por um pastor que os conduza. Quando reduziam o trabalho a um passatempo (um mau passatempo!) e ao desistirem do que é penoso, buscavam a comodidade. Desejavam extinguirem-se passivamente, um nada de vontade, o que, no nosso entendimento, se produz na vivência do que está instituído nos locais de trabalho, ou seja, nas condições e organização do trabalho que constrange os trabalhadores, não se tratando, portanto, de responsabilizá-los por esse processo. Então, afirmar esse estado de coisas não significa negar os processos instituintes que os docentes engendram no curso de suas atividades, dado o caráter complexo e enigmático do trabalho. Mas, como dar visibilidade às estratégias criadas que se abriam à invenção, à problematização do instituído na escola, assumindo uma posição política que desnaturaliza a realidade vivida e aposta na transformação das práticas estabelecidas? Como potencializar estratégias concretas de ação que forjam a criação de novos mundos, de outros modos de vida-trabalho?

Um estado de anestesia e uma injeção letal de niilismo, quando aplicada à veia, podem preparar o caminho para a morbidade, muitas vezes constituído como formas de defesa e proteção encontradas para lidar com as políticas educacionais que podem produzir situações muito penosas. Em seguida, podem ser acionadas formas reativas desmobilizadoras e, assim, tudo conspurca para a desmobilização e a instalação de um 'estado-nãoestado' de não criação de si e do mundo e a ordem das coisas é admitida como tal (natural). 
Visávamos a transformar as adversidades, sentidas muitas vezes como motivo de desânimo ou desilusão, em desafios a serem enfrentados e o rebanho em 'companheiros', ou seja, seres vivos (e não cadáveres!), que não se deixam levar por nenhum pastor. Era preciso desgarrar muitos do rebanho, mas trabalhadores-companheiros não estão já dados, é necessário criá-los e isso só é possível no cotidiano do trabalho, desviando-nos do rebanho, criando "companheiros que escrevam novos valores" (Nietzsche, 2000, pág. 34). As condições adversas precisavam ser transformadas em dispositivos para a construção de outras/novas formas de organização do trabalho na escola.

'Desaprender' é uma das tarefas importantes nos processos de invenção da vida. 'Curricularizar'8 o cotidiano daquela escola era o desafio que para nós se colocava. Que realidade está presente nesse cotidiano e como são os organizadores dele?

Freqüentemente, percebíamos uma tentativa desesperada de criar estratégias para superar as dificuldades. Dificuldades pela falta de equipamentos básicos e de material adequado para as aulas, pelo excesso de alunos nas turmas, pela ausência de profissionais para trabalhar com os alunos portadores de deficiência, pelo espaço reduzido da escola, entre tantas outras. Para contornar essas situações, os professores muitas vezes traziam material de casa, faziam dois planejamentos de aula para a mesma turma, usavam o recreio como horário para tirar dúvidas das crianças, transformavam o pátio (que já era pequeno) em quadra de esportes e depois dividiam aquele espaço em dois para que os meninos e meninas pudessem ter a disciplina de Educação Física, já que não havia um local adequado para isso. Porém, nem sempre essas estratégias se sustentavam porque, na maioria das vezes, eram lutas individuais; cada um tentando fazer sua parte da melhor maneira que podia, do jeito que era possível. Em nossa perspectiva, entretanto, o caso de cada um ali é coletivo, “(...) pois vive dos dispositivos de produção de subjetividade atualmente em ação (...)" nas escolas (Rodrigues, 2000, p. 85). Do contrário, seriam mantidas as sensações de cansaço, impotência e solidão, constantes nas falas dos professores:

\footnotetext{
“Depois de 21 anos não agüento mais" (professora);

"Todos nós estamos doentes, todos trabalhamos doentes" (professora);

"Nós preferimos continuar da mesma forma porque é melhor 'pra' todo mundo" (professora);

“Nós estamos muito centrados em nós mesmos, cada um no seu trabalhinho, quietinho. Entramos na nossa salinha, damos a nossa aulinha, deu meio-dia a gente escapa, vai embora e estamos vivendo a nossa vida assim. Mas os problemas estão aí (...). Eu estou me sentindo só. Eu chego, dou bom-dia para todo o mundo, entro na minha sala, dou minha aula e vou embora. Mas os problemas
} 
não estão sendo discutidos com o grupo. Nós não conversamos umas com as outras. A verdade é essa" (professora).

A coletivização do que sentem e a troca de experiências são fundamentais para que os educadores percebam que não estão sozinhos nesse barco e que, conversando e compartilhando idéias e sentimentos, poderão ganhar força e buscar novos caminhos. É sempre preciso um 'cais' onde se possa saltar num navio qualquer e recolher as âncoras...

“A primeira grande transformação e de impacto importante para nós seria justamente mostrar que não é só um que está sofrendo; está todo mundo angustiado. Seria também estar registrando essas angústias e continuamente traçar caminhos e formas de lidar com os problemas" (professora).

Logo que chegamos à escola, tínhamos em mãos um esboço de roteiro de trabalho a ser seguido, pautado no projeto da pesquisa, o qual foi tomando corpo e também sofrendo alterações no decorrer do percurso que ia sendo trilhado por nós - grupo de psicologia e educadores. Buscávamos transformar a situação de privatização das práticas e as conseqüentes sensações de cansaço e subjetividades mortificadas.

O primeiro passo foi investigar como estava a situação atual daqueles educadores, suas condições de trabalho e a forma como se organizavam para realizar suas atividades. Para tanto, foi aplicado, em parceria com o Centro de Referência em Saúde do Trabalhador, um questionário contendo um inquérito epidemiológico, no qual se pesquisou o perfil sociodemográfico dos professores, a percepção sobre o ambiente de trabalho, os riscos, o SRQ 20 - instrumento de trabalho da OMS que identifica transtornos mentais menores em grupos populacionais -, as fontes de tensão e cansaço, o uso de substâncias ansiolíticas, os tipos de lazer, etc. Os resultados obtidos com a pesquisa quantitativa foram importantes para disparar discussões sobre as péssimas condições em que se encontram os trabalhadores da educação.

Os resultados demonstraram que a força de trabalho é prioritariamente feminina $(72,3 \%)$ com uma faixa etária predominante de $45,4 \%$ com até 40 anos, apontando esse trabalho como escolha para sobrevivência. $O$ elevado índice de transtornos osteomusculares $(40,9 \%)$ se associa aos mentais $(40,9 \%)$, como por exemplo, apatia, estresse, desesperança, paralisia e desânimo, que se fizeram representar de prevalência indicativa de transtornos mentais menores, o que reforça a situação de desgaste vivida pelos trabalhadores em seu trabalho na escola.

Ainda de acordo com a análise realizada a partir dos resultados obtidos com a aplicação do questionário, as principais fontes de tensão e cansaço estão relacionadas com tarefas repetitivas, ritmo de trabalho, ruído elevado, 
calor, flexão freqüente de tronco para ensino individual, elevação do membro superior direito, para os destros, acima dos ombros para escrita no quadro, espaço improvisado de sala de aula, iluminação deficiente, falta de material didático, número elevado de alunos/sala, dificultando a atenção individualizada, e presença de alunos com 'deficiência mental' nas salas (expressão utilizada pelos professores).

A análise ergonômica da atividade apontou, ainda, que o trabalho das professoras envolve uma enorme carga física que se estabelece pela permanência da educadora em posição ortostática durante $95 \%$ das atividades, com graus variados de flexão da coluna cervical. Destaca-se, também, uma organização do trabalho marcado pela atenção permanente, ritmo intenso de trabalho, necessidade de controle disciplinar, uso elevado da voz, número grande de alunos por turma, obrigando a professora a executar regulações para atender ao trabalho prescrito.

Esses dados foram utilizados para disparar um processo de mobilização visando a transformar essa situação. Era preciso construir estratégias para reverter esse estado de coisas, o que só se efetivaria se houvesse investimento por parte das trabalhadoras nessa direção.

Depois de algum tempo freqüentando a escola, criando laços, discutindo a situação preocupante das condições de trabalho, passamos para o passo seguinte e, a nosso ver, o mais importante: a tentativa de formar uma comunidade ampliada de pesquisa (CAP). Mas o que é isso? Queríamos articular os saberes que construímos na academia com os saberes dos próprios trabalhadores, para que, juntos, pudéssemos produzir novos modos de gestão do trabalho que possibilitassem a potencialização e a manutenção de espaços de análise e discussão coletiva, levando a intervenções tanto no ambiente quanto no próprio modo de ser educador (formação de um trabalhador-pesquisador). Um processo de formação que intencionava instituir na escola práticas de saúde pelas quais os trabalhadores pudessem detectar, interpretar e reagir às dificuldades cotidianas. É necessário, para isso, o diálogo que constitui um elemento fundamental para que se construa o conhecimento de trabalhadores e pesquisadores-especialistas sobre a relação saúde-trabalho. Dialogando, aprendemos a ouvir, entender e discordar, exercendo, assim, o debate e a crítica. Do diálogo intenso, o problema emerge em toda a sua complexidade, bem como suas possíveis saídas e alternativas (Athayde et al., 2003).

Para isso, entendíamos como necessário abordar temas que constituem e são constituídos no cotidiano escolar, como saúde, trabalho e gestão, currículo e CAP. Elaboramos alguns textos, programamos datas e buscamos, nos horários apertados, corridos, um espaço para a discussão e análise. A esses espaços coletivos denominamos oficinas, uma vez que a perspectiva era de 
que, ao final de cada encontro, tivéssemos um produto que pudesse se constituir em mais uma ferramenta para intervir na organização do trabalho.

Vale destacar que, quando falamos em formação, não estamos nos referindo apenas a um processo de assimilação de conteúdos, algo que antecede o fazer, mas a um modo de conhecimento que ocorre no dia-a-dia e que surge de indagações, dúvidas, incertezas. Formar é produzir análises potentes para a intervenção no cotidiano, tornando possível a problematização das nossas práticas, a reavaliação dos caminhos escolhidos e a busca de novas alternativas. É importante perceber que a formação se dá justamente no ato de pesquisar, de questionar. Pesquisa e formação estão, portanto, em um processo de retroalimentação contínua.

Os textos trabalhados nas oficinas buscavam marcar nossas diretrizes, valores e compromissos naquela pesquisa, já que não somos pesquisadores encastelados num lugar de neutralidade, não éramos observadores neutros. Isso significa, também, que não estávamos lá para dizer o que é melhor, apenas gostaríamos de construir coletivamente outras novas formas de agir e dar visibilidade ao que acontece o tempo todo e que, freqüentemente, é desvalorizado ou não tem visibilidade. Nossa intenção era que os textos servissem como disparadores das discussões, que, a partir deles, surgissem articulações com o próprio trabalho do educador, que cada um pudesse se apropriar daquele conteúdo, falar, debater, discordar, problematizar, pensar junto. Nosso objetivo era sempre colocar todos na roda, como "(...) espaço coletivo, arranjo onde exista oportunidade de discussão e de tomada de decisão" (Campos, 1999, p. 30).

Nossa preocupação ao longo do percurso foi envolver os educadores em um processo de pesquisa das condições de trabalho que pudesse alterar a situação vivida. Sabíamos que não seria uma tarefa nada fácil, na medida em que não foi uma solicitação da escola, mas uma oferta que veio do grupo de psicologia/Ufes, a partir de estudos e análises anteriores sobre a situação dos docentes da rede pública de ensino. Como sensibilizar os trabalhadores da escola para os efeitos produzidos em sua saúde frente às condições de trabalho tão precárias?

Todos os trabalhadores da escola eram convidados a participar das oficinas que, a princípio, tinham duas horas de duração e ocorriam quinzenalmente. As crianças eram liberadas após o recreio e nós, grupo de psicologia e educadores, nos reuníamos. No primeiro período letivo, as oficinas funcionaram da seguinte forma: inicialmente, a coordenadora da pesquisa situava os educadores sobre o tema da oficina do dia; em seguida, era realizada uma leitura silenciosa do texto que o grupo da Ufes havia construído; o próximo passo era a divisão dos educadores em pequenos grupos nos quais, então, realizávamos um debate sobre a temática em questão e suas relações com o cotidiano de trabalho na escola - cada grupo escolhia um rela- 
tor, que deveria apresentar, no grande grupo, as questões levantadas nos pequenos grupos; a última etapa era a discussão ampliada, quando buscávamos destacar as inquietações, os problemas vividos e, também, as estratégias que poderiam ser construídas para alterar o trabalho cotidiano.

Após o retorno das férias escolares houve algumas trocas de professores na escola. Fizemos uma reunião com os novos integrantes do corpo docente para saber se a eles interessava participar do grupo de pesquisa conjuntamente com seus colegas de trabalho. Como a resposta foi positiva, marcamos novas oficinas que seriam realizadas ao longo do ano. Porém, a dinâmica do trabalho se deu de uma outra forma: as oficinas deixaram de ser quinzenais e passaram a ser mensais, ocupando toda a manhã e não mais com duração de duas horas, pois percebemos que esse era um tempo muito reduzido para as discussões. O problema é que as crianças não poderiam ser liberadas. Enquanto os educadores estivessem nas oficinas de formação, precisávamos de pessoas para ficar com elas. Como nosso grupo é grande, lançamo-nos ao desafio. Mas não queríamos ir sozinhos, já que esse trabalho não era só nosso. Chamamos, então, alguns pais e mães para se unirem a nós.

As oficinas passaram a ter um outro formato: sempre levávamos um texto gerador que visava a disparar uma discussão, tendo como princípio a construção de estratégias para a transformação dos aspectos do trabalho que faz sofrer. Demos preferência aos textos literários, por considerarmos que possuem uma potência de problematização, como o estranhamento e a surpresa, pois, como nos indicou Deleuze e Guattari (2000), a arte em geral e a literatura em particular produzem experiências que transpõem os limites das formas subjetivas constituídas, acionando blocos de sensações, afectos e perceptos pré-subjetivos e impessoais.

A experiência de entrar na sala de aula, sentindo na pele o que é trabalhar com 30 crianças, coordenar uma escola tendo que manter um mínimo de ordem para que ela não virasse uma 'bagunça', se fazer ouvir, ficar na cantina distribuindo merenda, tudo isso foi extremamente desgastante, mas muito rico e instigante. Deparamo-nos com os imprevistos, com o não saber o que fazer, e aí acabávamos reproduzindo determinadas formas de fazer educação que muitas vezes criticávamos. Mas esse também foi um espaço de criação e aprendizagem. Pudemos perceber as dificuldades dos diversos trabalhos, a importância do saber-fazer que surge da experiência. É a merendeira que sabe a quantidade exata de leite para colocar em cada caneco de maneira que não falte para nenhuma criança; é a professora que diz que é melhor distribuir primeiro um exercício, esperar os meninos acabarem e depois entregar o outro, porque senão eles 'se embolam'; é a coordenadora que fala que o trabalho dela não se resume a inspecionar; é a mãe que faz um relato da experiência de participar por um dia do cotidiano da escola dizendo que o professor "tinha que ganhar era um milhão de reais"; é a cri- 
ança que te chama pelo nome, te abraça e diz que vai pesquisar também o que os colegas acham que é mais legal na escola. Nesses momentos, a divisão, muitas vezes clara, entre equipe técnica, professores, serventes, grupo de psicologia, pais e mães e alunos se diluía. Todos trabalhavam juntos, mesmo em funções e em âmbitos diferentes, todos participando da construção diária da escola! E, nesse processo, os laços se fortaleciam.

Entretanto, em alguns momentos, sentíamos que o trabalho emperrava. Ninguém conseguia sair do lugar. As pessoas se mostravam desinteressadas, ou então ocupadas demais e os laços pareciam afrouxar de novo. Aí batia o desânimo, a vontade de desistir, de abandonar tudo. Mas esses altos e baixos só fortaleciam a idéia de que a vida não é linear; que algo pode dar certo em um momento, e no outro, não, e que esse movimento não desqualifica o que já foi feito, mas mostra que as estratégias devem ser pensadas e reavaliadas cotidianamente.

As oficinas foram se constituindo ao longo do processo como espaços coletivos muito importantes, nos quais os educadores podiam discutir o seu próprio trabalho e perceber os movimentos que faziam a escola funcionar e os que a paralisavam. Debates acalorados foram travados, alguns fortemente carregados de culpabilização e de momentos catárticos quando as pessoas se acusavam e se defendiam. Em outros, puderam ser analisadas as relações cristalizadas de trabalho, surgindo propostas efetivas de transformação. De uma das oficinas saiu a proposta dos educadores de uma avaliação bimestral do trabalho, que se constituiria em um espaço onde as dificuldades pudessem ser coletivizadas, as experiências trocadas, reflexões provocadas entre os educadores, sem a presença direta do grupo de psicologia, criando outros espaços para analisar e discutir o seu trabalho e o que este está produzindo. Enfim, um local onde as lamentações se revertessem em ações.

Ainda como produto dos trabalhos nas oficinas, foi instituído um grupo que se responsabilizou por fazer um levantamento com os outros integrantes da escola e do bairro sobre o que produz adoecimento e quais as propostas para mudar essa situação, visto que as discussões giravam em torno de uma 'falta de motivação' e de uma sensação de impotência paralisantes. Esse grupo foi constituído por pessoas de diferentes setores da escola: uma mãe, que é também representante do conselho de escola; uma professora; a pedagoga; uma servente; e duas pessoas do grupo de psicologia que, durante o período de cerca de um mês, se reuniram semanalmente. Em um primeiro momento, foram elaboradas quatro questões que seriam pesquisadas com os outros educadores, com o intuito de que todos pudessem levantar problemas e soluções que considerassem mais importantes, a fim de que se montasse um quadro de prioridades de ações que servisse como um dispositivo usado para efetivá-las. As questões seguem: 


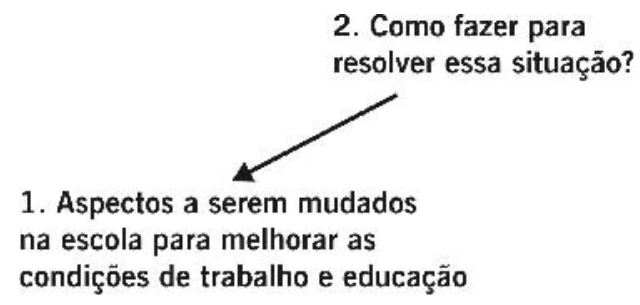

4. De que forma a comunidade pode contribuir para melhorar a escola?

na escola para melhorar as

condiçöes de trabalho e educação

3. Situações ocorridas na escola que promovem saúde

Em relação à primeira questão, as respostas que mais apareceram foram referentes ao barulho que, naquela escola, especificamente, era um problema muito sério, visto que o espaço físico era extremamente pequeno, não havia refeitório e a quadra de esportes era o próprio pátio com algumas marcas no chão que delimitavam uma quadra, dividida pelas crianças entre o vôlei, o futebol, a queimada, o corre-corre, a merenda, os grupinhos de amigos etc. Era muita energia para pouco espaço, o que provocava um barulho ensurdecedor. Como se não bastasse, o lugar onde era feita a aula de Educação Física ficava ao lado da biblioteca (muito pequena) e justamente embaixo de algumas salas. Logo, os professores que ali davam aula tinham que gritar, se quisessem ser ouvidos. Outras respostas também apareceram com freqüência, como: maior integração da equipe, melhores equipamentos, presença do diretor no cotidiano escolar, respeito por parte dos alunos, maior cobrança e compromisso dos pais com seus filhos, mais cooperação entre os profissionais, melhor comunicação entre os professores, respeito mútuo, maior participação dos pais nas questões da escola, merenda de melhor qualidade (respeitando o cardápio do dia), melhor salário.

Já na segunda questão, referente ao que fazer em relação aos problemas apontados, as respostas que surgiram muitas vezes se confundiam com as da primeira questão: construir uma nova escola, buscar soluções em equipe, valorizar os educadores por parte da coordenação da Seme e pelos outros profissionais da escola, exigir a presença do diretor com maior freqüência nas questões relativas à organização das atividades, realizar reuniões sistemáticas com os pais, estabelecer limites aos alunos, promover diálogo entre os professores. 
Em relação à terceira questão, que diz respeito ao que produz saúde na escola, as respostas foram as seguintes: companheirismo, carinho dos alunos, percepção de que o seu trabalho está rendendo, proximidade do corpo docente com o discente, troca de experiências, bate-papo no recreio, comemorações, trabalho coletivo. É interessante notar que o que os educadores apontam aqui como gerador de saúde refere-se ao que faz o trabalho ganhar sentido para eles, quando percebem a importância do que fazem e são reconhecidos como participantes desse processo. O relato da professora de Educação Artística é um depoimento importante nessa direção:

“Era a semana de culminância do Projeto de Bairro, que era um projeto no qual as crianças tinham que pesquisar sobre o bairro em que residiam, como uma maneira de aproximar as questões da comunidade extra-escolar com a escola. Os trabalhos foram divididos por série e cada turma ficou responsável por determinadas atividades. As primeiras séries iam trabalhar com desenhos, as segundas séries com maquetes e as terceiras séries com a linha do tempo. Eu fiquei de ajudar as outras professoras, entretanto alguns percalços apareceram. No dia em que ia trabalhar as maquetes, tive uma discussão com a coordenadora por causa de um atraso meu e ela não forneceu o material necessário para a realização da atividade. Sem saber o que fazer com a turma, que estava muito agitada, resolvi falar sobre História da Arte e passei alguns exercícios para as crianças copiarem. Entretanto, a professora da turma achou que eu estava castigando as crianças com exercícios e coisas que elas não entendiam. Então a pedagoga falou que eu teria que mudar de método. Fiquei muito chateada e decidi que não ia trabalhar mais nada de interpretação e que eu ia trabalhar apenas com desenhos. Porém, quando fui trabalhar com a primeira série, que era justamente desenho, percebi que eles já haviam feito aquela atividade que eu havia programado com a professora e ninguém havia me avisado disso. Como não queria fazer a mesma coisa com eles, pois ia ficar muito chato, então resolvi retomar a interpretação de textos que eu havia abandonado por causa de críticas de professores de que as crianças não entendiam aquilo. Eu trabalhei com os meninos da primeira série o mesmo texto que eu dei para os de terceira e fiquei muito feliz com o que aconteceu. Eu estava trabalhando com texto sobre os primórdios da arte, das pinturas nas cavernas e perguntei para eles o que entendiam sobre isso. A resposta deles foi muito legal: ‘Eu sei, professora, é como no desenho animado dos Flintstones. Essas pinturas são da época em que as pessoas cortavam as coisas com pedra.' Quando pedi para desenharem o que eles achavam que essas pessoas desenhavam nas cavernas, eles fizeram animais e pessoas com flechas. Eu percebi que eles estavam entendendo tudo o que eu dizia, e mais, que eles estavam compreendendo o texto e interpretando. E olha que eu ouvi de professor que eles não entendiam isso. Entretanto, eles fizeram as atividades rápido e eu tinha duas aulas para dar. Então eu fiquei pensando: 'Meu Deus, o que vou fazer?' Aí eu lembrei que eu tinha um livro de 
história na minha pasta e resolvi contar uma história para eles. E eles adoraram a história.

Essa tensão que o trabalho provoca é escoada pelo retorno que os alunos te dão. Quando eu estava contando a história e vi que eles estavam com os olhinhos quase saltando para fora, superinteressados, aquele silêncio, todos quietinhos, aquilo me deixou muito feliz. Eu saí da sala e tinha deixado para lá tudo o que tinha acontecido, os aborrecimentos que eu tinha passado, porque aquele momento recompensou. E pensar que o livro não estava planejado, que ele estava por acaso dentro da minha pasta, porque eu dou aula em outra escola e eu estava trabalhando ele [sic] com uma outra turma. Foi pensado no momento da aula, quando eu não sabia o que fazer, e deu certo."

A quarta questão traz à tona a relação escola-comunidade, que era muito questionada pelos educadores e que sempre aparecia nas oficinas na forma de queixa. É interessante pontuar que o que os professores chamavam de comunidade, na maior parte das vezes, referia-se aos pais e mães dos alunos ou pessoas responsáveis por eles. As respostas de como a comunidade poderia contribuir com a escola foram as seguintes: cuidar melhor dos filhos, acompanhá-los na sua caminhada pela escola, participar dos eventos e comemorações que a escola promove, dar soluções para problemas de alunos indisciplinados, dar continuidade dentro de casa ao processo de ensino-aprendizagem, comparecer e participar das reuniões, do conselho de escola, confiar mais na escola, ajudar sempre que for requisitada, ser parceira da escola, trabalhar juntos para solucionar problemas pertinentes à comunidade escolar.

Após pesquisar como os educadores da escola percebiam essas questões e o que pensavam que poderia ser feito, o grupo de trabalho reuniu todas as respostas dadas e organizou-as, tirando alguns focos que centralizariam as ações. A intenção era criar uma estratégia em que os próprios trabalhadores se envolvessem na luta pela melhoria das situações vividas na escola. Dessa maneira, cada grupo se responsabilizaria por um foco, mas com a preocupação de coletivizar as ações e decisões. Esses focos se direcionaram para situações que necessitavam de mudanças mais urgentes: diminuição do barulho/mudança do espaço físico, melhores equipamentos, aumento de salário, definir limites para os alunos, relacionamento interpessoal, participação mais ativa da comunidade nas reuniões e parcerias de toda a comunidade (escolar e extra-escolar) para o trabalho na escola.

Posteriormente, os dados obtidos pelo grupo de trabalho, após o levantamento realizado com os educadores (focos), foram levados para a discussão em uma outra oficina, na qual foram feitos encaminhamentos e votadas propostas de como criar condições para transformar a situação, ou seja, o 'como' fazer. Para isso, foram sugeridas reuniões com a comunidade, 
com o sindicato, entre os turnos, com a própria equipe para a troca de experiências, além de uma relação mais direta com a direção da escola, quebrando algumas hierarquias que dificultavam as ações. O passo seguinte foi decidir 'quem' se responsabilizaria pelos focos, ou seja, a partir dos debates seriam criadas comissões para operacionalizar as ações além de estabelecer um prazo para a entrega de alguns resultados ('quando').

Entretanto, muitas das determinações definidas pelo coletivo não foram efetivadas e o grupo falava de um desânimo e de dificuldades em alterar o estado de 'coisas' vivido.

“É como se nós tivéssemos [sic] num navio e tivesse alguém para mudar, nós preferimos jogar ele [sic] no mar do que ele ficar dentro do navio para incomodar."

"Nós achamos que é mais fácil deixar do jeito que está do que investir na mudança."

"Às vezes a gente sofre menos mantendo as coisas como estão do que ter que mudar."

Esses acontecimentos - que sinalizavam descrédito por parte dos educadores quanto à possibilidade de alterar a situação vivida - apontavam a urgência de se construir outras estratégias que produzissem bifurcação em relação a essas formas despotencializadas de funcionamento. Portanto, era necessária uma avaliação do processo experimentado de forma a construir novos caminhos. Essa avaliação foi fundamental para que nós, grupo de psicologia e educadores, entendêssemos melhor as implicações de cada um no processo vivido. Essa avaliação contou com a participação de outros profissionais da Psicologia da Ufes que tiveram a função de coordenar a oficina.

O método usado pelos coordenadores da oficina foi a produção de uma encenação 'muda', utilizando recursos corporais, mímicos, expressivos e as 'bolhas' - usadas em histórias em quadrinhos para evidenciar diversos pensamentos e sentimentos. O tema disparador do processo foi: 'Como vivemos estes encontros entre a escola municipal e a Ufes no turno matutino: o começo, as expectativas e o caminho percorrido?'.

Em um primeiro momento, foram divididos três grupos: dois com o pessoal da escola e um composto pelo grupo de psicologia. Foi dado algum tempo pelos coordenadores para que as pessoas preenchessem as bolhas com o que sentiram e pensaram durante essa caminhada juntos. Em seguida, essas falas foram encenadas. Tanto os educadores quanto o grupo de Psicologia trouxeram as dificuldades em construir um outro modo de viver e trabalhar que busque problematizar o cotidiano e investir nele para conquistar mudanças. 
Muitas falas apontaram um individualismo exacerbado, fruto de um sistema econômico e social que colabora para a formação de uma subjetividade calcada no eu, fortalecendo um ciclo vicioso de lamentos, de reprodução de uma lógica que homogeneíza e apaga as diferenças conflitantes, não abrindo espaço a uma possível transformação coletiva.

"Nós esperávamos que vocês resolvessem nossos problemas, quando percebemos que para isso teríamos que nos mobilizar, perdemos o tesão."

“O grupo de psicologia fez o que pôde, mas nós não estamos querendo mudar, é mais fácil manter as coisas como estão."

"Vocês fizeram o que foi possível, mas não deu (...). Nós somos muito acomodadas."

"Eu não quero acreditar que não é possível. Eu continuo acreditando que podemos mudar."

"Quando vocês chegaram aqui eu pensei que nós íamos crescer, mas não aconteceu muito."

“(...) no começo teve algumas mudanças sim, mas depois, não foi por culpa de vocês, mas um comodismo nosso também."

"Nós preferimos continuar da mesma forma porque é melhor pra todo mundo."

"Nunca passou na minha cabeça que essa desmotivação que tanto falávamos e vivíamos vocês também estavam sentindo."

“(...) resistência ao novo. Construção histórica do mundo individualizado. Quero sair do individualismo, por isso é que venho para esses encontros."

"Sinto uma sensação de esvaziamento. Não sinto o que posso pegar para alavancar o grupo."

“(...) de repente vocês podem estar querendo colher rápido a sementinha que foi plantada nesses encontros."

“Muitas expectativas, ansiedades, esperança, participação, acomodação, desestímulo (...)."

"A esperança é a última que morre!"

“Depende de nós o sucesso! Ou o insucesso!"

“Devemos ter fé!"

"Ah! Se tudo o que foi trabalhado fosse concretizado!"

"Que bom, até que enfim alguém se preocupou com a saúde do profissional de educação! Será que vamos colocar em prática?"

“Eu acho as crianças estressantes, por isso os professores não têm ânimo para participar de outros assuntos (eventos). Diante de tantos problemas com as crianças, tendo que atender aos pais, falta de materiais."

"Eu estou aqui porque acredito em vocês. [E em você?]. Em mim também."

"Somos covardes, precisamos vencer."

"Acho que falta amor. Só falamos o negativo dos outros, não estamos prontos para ajudar!" 
"Será que as estratégias que utilizamos foram boas?"

"E agora! O que estamos esperando?"

“Desisto."

Mas o que estariam sinalizando essas falas? Quais os desafios que elas nos impõem? Como aumentar o quantum de comunicação desses grupos? Como produzir grupos sujeitos na escola, marcados por uma dinâmica de abertura, uma dinâmica analítica que produza a ruptura das formas instituídas? A experiência desse último encontro na escola nos impulsionou a pensar novas estratégias de ação... As falas apontavam uma expectativa frustrada, ou seja, de que os psicólogos resolvessem os problemas vividos na escola, o que reafirmava os resultados obtidos na primeira fase quando utilizamos o SRQ 20, ou seja, desânimo, paralisia e descrédito na potência de ação que possuem. Essas questões foram trazidas para a análise e, dessa forma, foi possível discutir estratégias para produzir outras formas de inserção na escola. Utilizamos o dispositivo grupo visando a promover mudanças nos modelos de educação e de gestão da escola. Os diferentes lugares foram questionados, a hierarquia, a concepção de educação que se materializava nas práticas. Na trilha da abordagem ergológica, a partir de uma 'clínica da atividade' 9 , focalizamos aquele coletivo e aquele ambiente de trabalho, confrontando os saberes práticos dos docentes e o conhecimento dos psicólogos, de forma a entendermos a gênese daqueles processos de adoecimentos que se expressavam nas diferentes formas de paralisia e descrença. Conforme Hubault (2004, p. 124) a ergonomia pertence à família das abordagens clínicas, em que o conhecimento deve-se à pertinência, ou não, do “(...) caso particular, histórico, no qual reside a validação". Foi nessa direção que oportunizamos trocas nos grupos que viabilizaram o debate da situação singular vivida naquela escola, de forma que os docentes pudessem viver a experiência de trabalho e, assim, construir formas de intervir coletivamente sobre a nocividade do trabalho que desempenhavam.

\section{“Não vamos desistir: saúde é luta!"10}

O processo vivido na escola vem afirmar a perspectiva de saúde que temos adotado: saúde como a possibilidade de produzir novas normas, novas formas de vida (Canguilhem, 2001). Pensar a saúde é pensar a vida. Como anda a vida nessa escola? Promover saúde é pensar a qualidade de vida, mas o que é qualidade de vida? Essa resposta não é unânime, universal ou geral, mas depende dos diferentes agrupamentos humanos. Pensar promoção de saúde é pensar estilos de vida singulares e isso inclui a participação dos envolvidos nas diferentes situações desse processo. 
Não basta perguntar a cada um como está na produção da sua saúde, como tem feito. Não se trata de pensar em si mesmo, pois a vida não é algo que se passa apenas em cada um, mas, principalmente, entre os sujeitos, na construção de redes sociais, redes de vida. É na vida que se passa entre os sujeitos que a vida de cada um pode acontecer. Ninguém consegue viver sozinho, isolado. Logo, pensar a vida é pensar o que passa entre nós, o padrão de vida é a rede. É na troca que a vida vai ganhando expressão, na possibilidade de afetar e ser afetado.

Os humanos inventam o modo como vivem, o que não significa que seja a melhor maneira. Os humanos, ao se inventarem, inventam a vida, inventamos novos problemas para viver diferente.

Fazemos referência a essas questões neste momento porque vislumbramos que o vivido na escola indica um processo, mesmo que ínfimo, de promoção de saúde na direção que estamos apontando. Nossa ética, nossas atitudes se voltam para a promoção de saúde exatamente quando não nos preocupamos apenas com a nossa situação particular, já que estamos sempre em rede. O que define o humano é, exatamente, essa capacidade de criar, de propor alternativas.

$\mathrm{Na}$ escola são vividos muitos conflitos que falam de modos diferentes de pensar o trabalho educacional. Entretanto, as oficinas buscaram fazer as diferenças entrarem em contato, criando uma zona de tensionamento, e usar essa zona para fazer outra coisa. Promover saúde é trabalhar com essa zona, pois o que se passa entre nós é o que nos constitui. Essas zonas de encontro vão desestabilizar o que sabemos ou o que somos, forçando-nos a pensar os processos de comunicação, de troca. Lidar com as diferenças, com esse tensionamento, entrar numa zona de contato, estabelecer aproximação, é se aproximar dessa zona de tensionamento, é promover saúde.

As situações vividas na escola, e que se explicitaram nas oficinas, indicam-nos que esse processo de comunicação não se efetiva de forma mecânica, numa linha direta entre aquele que emite uma informação e o que a recebe, e sim por meio de uma rede constituída por diferentes vetores. É preciso lidar com essas redes de saber, de poder, enfim, com as diferentes redes que constituem esse processo comunicativo.

O que propusemos por meio das oficinas e demais encontros grupais foi promover saúde nesse local de trabalho pensando nas configurações dessas redes, quando, então, a comunicação se viabiliza. É preciso criar algo em comum entre nós. A tarefa não é das mais fáceis, mas um grande desafio.

Nessa linha de análise, consideramos que o vivido na escola, as situações de impasse, os momentos de desânimo e apatia falam da dificuldade de lidar com uma zona de tensionamento que se produz nas relações que se efetivam entre os humanos. Estariam os educadores daquela escola dispostos a enfrentar os embates advindos das diferentes formas de lidar com o 
trabalho que ali se atualiza? Como enfrentam essa zona de tensionamento? A adesão dos educadores à escola diz de uma vontade de transformação dos modos de trabalho que ali se atualizavam ou esses modos de funcionamento indicam uma dificuldade de enfrentar as tensões, as diferenças, as posições diferenciadas do viver?

Cabe destacar que alguns movimentos mais potentes e inventivos foram sinalizados. Os processos em curso indicam a importância de se ampliarem as pesquisas nesse campo com o objetivo de construir materiais metodológicos que nos auxiliem em estudos com essa direção ético-política, pois discordamos da afirmação de que a imensa maioria dos humanos não tem desejo de fazer trabalhos inventivos, de pensar, problematizar o instituído, criar formas mais potentes de viver-trabalhar. Ao contrário, onde há trabalho humano há variabilidade, criação, gestão, história. Em toda atividade de trabalho, há uma pluralidade de registros ou elementos que são articulados. Como nos diz Schwartz (2002, p. 134), “Não se governa o uso industrioso de homens e mulheres $(\ldots)^{\prime \prime}$.

\section{Notas}

1 Professora do Departamento de Psicologia e do Programa de Pós-Graduação em Educação da Universidade Federal do Espírito Santo (Ufes). Doutora em Educação Brasileira e Pós Doutora em Saúde Pública. < betebarros@uol.com.br>.

2 Pesquisadora do Núcleo de Estudos e Pesquisa em Subjetividade e Política do Departamento de Psicologia da Universidade Federal do Espírito Santo (Ufes). <zorzal07@terra.com.br>.

3 Pesquisadora do Núcleo de Estudos e Pesquisa em Subjetividade e Política do Departamento de Psicologia da Universidade Federal do Espírito Santo (Ufes). $<$ fernandasalmeida@gmail.com $>$.

4 Pesquisadora do Núcleo de Estudos e Pesquisa em Subjetividade e Política do Departamento de Psicologia da Universidade Federal do Espírito Santo (Ufes). $<$ rozacche@hotmail.com>.

5 Pesquisadora do Núcleo de Estudos e Pesquisa em Subjetividade e Política do Departamento de Psicologia da Universidade Federal do Espírito Santo (Ufes). $<$ vigoviapsi@hotmail.com>.

6 Os conceitos de tarefa, atividade, trabalho prescrito e trabalho real utilizados no texto vêm da ergonomia de língua francesa. 'Trabalho prescrito' é um conjunto de condições e exigências a partir das quais o trabalho deverá ser realizado (Montmollin, 
1995). As prescrições, que são as 'tarefas' fixadas a princípio, não consideram as atividades complexas necessárias na operação real; elas são uma ficção, afirma Dejours (1997). Referem-se ao que deve ser feito para se alcançar os objetivos do que foi prescrito. O 'trabalho real', por outro lado, fala do que no mundo se faz conhecer por sua resistência ao domínio técnico e ao conhecimento científico, aquilo sobre o qual a técnica fracassa depois que diferentes recursos da tecnologia foram utilizados (Dejours, 1997). É aquilo que escapa e se torna, por sua vez, um enigma a decifrar e emerge da singularidade em operação do humano, de trabalhadores que, mesmo com as estratégias da gerência capitalista, resistem à disciplina produtiva de “(...) subjetividades individualizadas e idiotizantes" (Athayde, 1999, p. 210). A 'atividade de trabalho' consiste na realização do trabalho prescrito, considerando-se as restrições e as vantagens dispostas pelas variabilidades do trabalho, ou seja, “(...) a maneira pela qual as pessoas se engajam na gestão dos objetivos do trabalho, num lugar e num tempo determinados, servindo-se dos meios disponíveis e inventando outros meios" (Alvarez e Telles, 2004, p. 71-72).

7 A idéia de niilismo aqui utilizada parte de Nietzsche (2000). É o niilismo entendido como um sentimento em que a vida tem um valor de nada na medida em que é negada, depreciada.

8 Curricularizar o cotidiano tem, aqui, o sentido de construir um currículo que tenha como matéria-prima o cotidiano da escola.

9 Conforme Athayde e Figueiredo (2004), o vocábulo clínica não envolve, para nós, a adoção de uma teoria do sujeito. "Remetemos a um determinado regime de produção de conhecimento pertinente ao caráter sempre enigmático e singular do trabalho. Um regime de co-produção, engajado em um espaço de colaboração entre os meios (milieux) de trabalho-racionalidade da ação e o meio científico-racionalidade científica" (p. 245). A proposição de uma clínica da atividade no âmbito da abordagem ergológica considera que a análise do trabalho é sempre, de algum modo, uma clínica do trabalho. Nessa perspectiva, segundo esses autores, está colocada uma perspectiva do “(...) materialismo epicurista, presente no conceito de clinamen (...), que se refere a um movimento dos átomos a partir do qual se criam coisas e movimentos, por meio de um processo que não implica regra de tempo, nem lugar. Nessa cosmologia clinamen designa o desvio que permite aos átomos caírem no vazio, entrarem em colisão e se articularem na composição das coisas" (p. 245). Ao nos apropriar da expressão clinamen, estamos pensando, portanto, numa abordagem clínica do trabalho como uma intervenção na produção e afirmação de um desvio, na criação de novos territórios existenciais. As contribuições de Yves Clot (1992) para uma psicologia do trabalho também nos orientaram nessa ação, uma vez que Clot propõe uma clínica da atividade e dos meios de trabalho, que opera entre subjetividade e atividade.

10 Esta frase foi retirada de uma das falas surgidas na oficina. 
ALVAREZ, Denise; TELLES, Ana Luiza. 2004. Interface ergonomia-ergologia: uma discussão sobre trabalho prescrito e normas antecedentes. In: ALVAREZ, Denise et al. (org.). Labirintos do trabalho: interrogações e olhares sobre o trabalho vivo. Rio de Janeiro: DP\&A. p. 63-90.

ATHAYDE, Milton; BRITO, Jussara; NEVES, Mary Yale (org.). 2003. Caderno de textos: programa de formação em saúde, gênero e trabalho nas escolas. João Pessoa: Universitária/UFPb.

; FIGUEIREDO, Marcelo. 2004. Coletivos de trabalho e componentes subjetivos da confiabilidade em sistemas sociotécnicos complexos: considerações a partir da situação de trabalho em mergulho profundo na Bacia de Campos/RJ. In: ALVAREZ, Denise et al. (org.). Labirintos do trabalho: interrogações e olhares sobre o trabalho vivo. Rio de Janeiro: DP\&A. p. 241-275.

1999. Psicologia e trabalho: que relações? In: MANCEBO Deise; JACÓVILELA, Ana (org.). Psicologia social: abordagens sócio-históricas e desafios contemporâneos. Rio de Janeiro: Eduerj.

CAMPOS, Gastão Wagner de Souza. 1999. Equipes de referência e apoio especializado matricial: um ensaio sobre a reorganização do trabalho em saúde. Ciência e saúde coletiva, Rio de Janeiro, vol. 4, n. 2, p. 393-404.

CANGUILHEM, Georges. 2001. Meio e normas do homem no ambiente de trabalho. Proposições, vol. 12, n. 2-3, p. 109-121, jul./nov.

CLOT, Yves. 1992. Le normal et le pathologie en psychopatologie du travail: une lecture différente du rapport trabailsanté mentale. Revue Canadienne de Santé Mentale Communautaire, vol. 11, n. 2.

HUBAULT, François. 2004. Do que a ergonomia pode fazer análise? In: DANIELLOU, François (coord.). A ergonomia em busca de seus princípios: debates epistemológicos. São Paulo: Edgard Blücher, p. 105-140.

DEJOURS, Christophe. 1997. O fator humano. Rio de Janeiro: ed. Fundação Getulio Vargas.

DELEUZE, Gilles. 1976. Nietzsche e a filosofia. Rio de Janeiro: Editora Rio.

GUATTARI, Félix; DELEUZE, Gilles. 2000. o que é filosofia?. Rio de Janeiro: Editora 34.

MONTMOLLIN, Maurice de. 1995. Ergonomie et organisation du travail. In: MONTMOLLIN, Maurice de. (org.). Vocabulaire de l'ergonomie. Toulouse: Octares.

NIETZSCHE, Friedrich. 2000. Assim falou Zaratustra: um livro para todos e para ninguém. Rio de Janeiro: Civilização Brasileira.

RODRIGUES, Heliana Conde de Barros 2000. Direitos humanos e intervenção clínica. In: RODRIGUES et al. Psicologia, ética e direitos humanos. São Paulo: Casa do Psicólogo, p. 54-68.

SCHWARTZ, Yves. 2002. Disciplina epistêmica, disciplina ergológica. ProPosições, Campinas, vol. 13, n. 1, jan./abr.

2003. Seminário trabalho e saber. Conferência de abertura do Seminário Trabalho e Saber, Belo Horizonte, 12 maio.

Recebido em 23/06/2006

Aprovado em 28/09/2006 